\title{
Powdertec Japan '88
}

The 7th Powdertec Japan, the biannual exposition of powder processing apparatus and equipment, was held at the International Trade Center in Harumi, Tokyo November 7 through 11. Exhibitors and visitors significantly increased compared to the previous expositions. A total of 201 exhibitors displayed their products and 81,000 people visited the exposition. (The total number of exhibitors and visitors at the previous exposition was 164 and 74,000 , respectively.)

As a special program, a booth for displaying powder measuring, testing, or controlling facilities was provided, as well as two "Powder Squares." In this booth, 25 exhibitors displayed their products.

November 8 through 11, the Powder Technology Congress ' 88 was also held at Hotel Urashima, located near the exhibition center, to discuss the following 7 categories in 7 individual sessions. A total of 36 lectures were given at these sessions.

- Powder technology for pioneering the 21 st century

- Design and evaluation of functional powder

- Fine particle relating technology supporting new material/composite material development

- Synthesis of functional powder and design of ceramic structure

- Electrostatic behavior of fine particles and their applications

- Promoting FA (factory automation) and utilization of AI (artificial intelligence) in the powder processing industry

- The latest technology relating to sub-micron particles
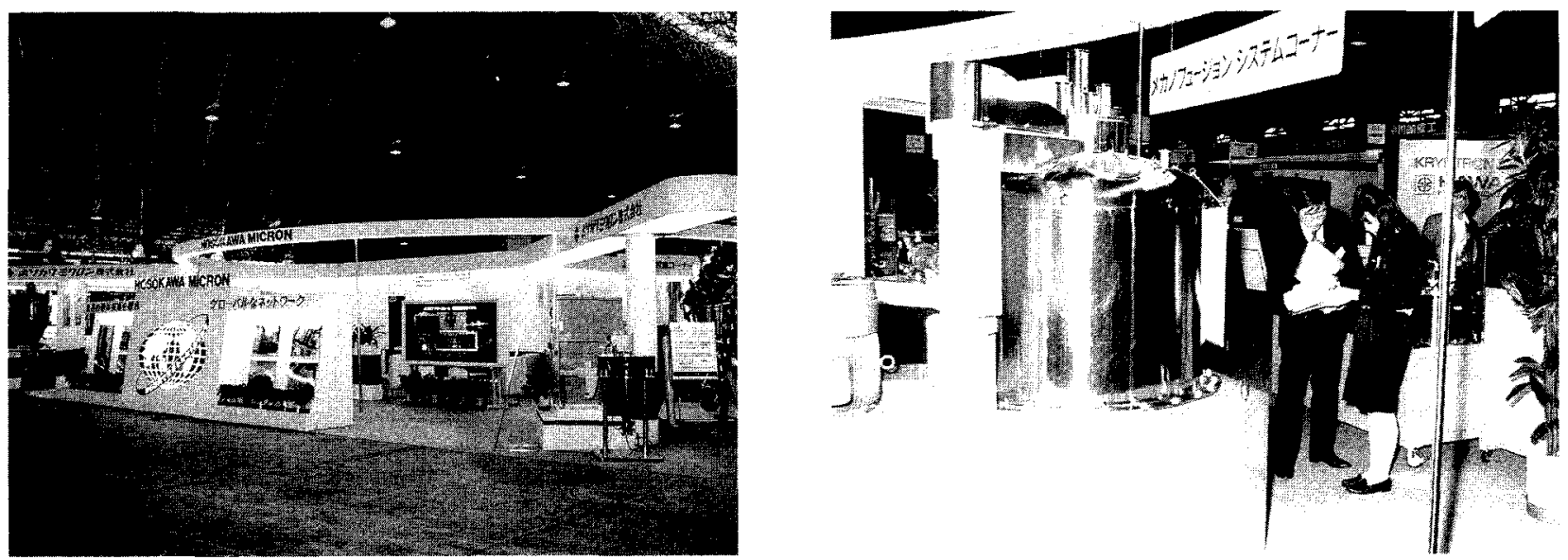

Photos: Powdertec Japan '88 